\title{
Both Talin-1 and Talin-2 correlate with malignancy potential of the human hepatocellular carcinoma MHCC-97 L cell
}

\author{
Kun-peng Fang ${ }^{1}$, Wei Dai ${ }^{2}$, Yan-Hong Ren ${ }^{2}$, Ye-Chuan $\mathrm{Xu}^{2+}$, She-min Zhang $^{2+}$ and Ye-Ben Qian ${ }^{1,2^{*+}}$
}

\begin{abstract}
Background: Talin-1 (TLN-1) and TLN-2 are implicated in many cellular processes, but their roles in hepatocellular carcinoma (HCC) remain unclear. This study aimed to assess cell cycle distribution, anoikis, invasion and migration in human HCC MHCC-97 L cells.

Methods: MHCC-97 L cells, which highly express TLN-1, were transduced with TLN-1 shRNA (experimental group) or scramble shRNA (negative control group); non-transduced MHCC-97 L cells were used as blank controls. TLN-1 and TLN-2 mRNA and protein levels were detected by real-time RT-PCR and western blot, respectively. Then, cell cycle distribution and anoikis were assessed by flow cytometry. In addition, migration and invasion abilities were assessed using Transwell and cell scratch assays. Finally, a xenograft nude mouse model was established to further assess cell tumorigenicity.
\end{abstract}

Results: Compared with the blank and negative control groups, TLN-1/2 mRNA and protein levels were significantly reduced in the experiment group. TLN-1/2 knockdown cells showed significantly more cells in the G0/G1 phase (79.24 \%) in comparison with both blank (65.36\%) and negative (62.69\%) control groups; conversely, less cells were found in G2/M and S phases in the experimental group compared with controls. Moreover, anoikis was enhanced $(P<0.05)$, while invasion and migration abilities were reduced $(P<0.05)$ in $T L N-1 / 2$ knockdown cells compared with controls. TLN-1/2 knockdown inhibited MHCC-97 L cell migration (Percentage of wound healing area: experimental group: $32.6 \pm 0.7 \%$ vs. negative controls: $50.1 \pm 0.6 \%$ and blank controls: $53.6 \pm 0.6 \%$, both $P<0.01$ ). Finally, the tumors obtained with TLN-1/2 knockdown cells were smaller $(P<0.05)$ compared with controls.

Conclusion: Both TLN-1 and TLN-2 levels correlate with tumorigenicity in human HCC, indicating that these molecules constitute important molecular targets for the diagnosis and/or treatment of HCC.

Keywords: Hepatocellular carcinoma (HCC), Talin-1, Talin-2, Migration, Invasion, Cell cycle arrest

\section{Background}

Hepatocellular carcinoma (HCC) is a major health problem [1]. Recent studies have reported an incidence of 780,000cases/year for HCC, with most individuals diagnosed at intermediate or advanced disease stages, where curative approaches are often not feasible [2]. Although there is no definitively curative treatment for HCC, multiple therapeutic and management options exist with

\footnotetext{
* Correspondence: qianyeben@hotmail.com

'Equal contributors

'The People's Hospital, Xuancheng City, Auhui Province, China

${ }^{2}$ First Affiliated Hospital of Anhui Medical University, Hefei 230032, Anhui Province, China
}

various advantages and disadvantages [3]: the surgical options include resection, transplantation and ablation; in addition, radiation therapy and biologic agents such as Sorafenib have been proposed.

Two talin genes present in vertebrates, namely Talin-1 (TLN-1) and Talin-2 (TLN-2), encode proteins with $74 \%$ sequence identity; TLN-2 is the ancestral gene, with TLN-1 arising by gene duplication early in the chordate lineage [4-7]. Despite the high homology between both talin proteins, differences in the remaining amino acids may affect protein function $[8,9]$. TLN-1 is primarily expressed in the kidney, liver, spleen, stomach, lung, and vascular smooth muscle [5,10-13]. Additionally, 
TLN-2 mRNA expression is most abundant in the heart, brain, and skeletal muscle $[5,13]$. However, other recent western blotting data and expression studies with a mouse gene trap line have suggested that TLN-2 may be more widely expressed $[5,14,15]$.

TLN-1 is a cytoskeletal protein of $270 \mathrm{kDa}$ that plays a pivotal role in regulating the activity of the integrin family of cell adhesion proteins by coupling them to F-actin [16, 17]. TLN-1 is also a focal adhesion protein that binds to multiple adhesion molecules, including integrins, vinculin, focal adhesion kinase (FAK), and actin. Moreover, TLN-1 plays an essential role in integrin activation $[18,19]$. Upon activation, integrins increase the functional interaction between cells and the extracellular matrix (ECM), thus serving as bidirectional transducers of extracellular and intracellular signals, ultimately regulating adhesion, proliferation, anoikis, survival, and tumor progression [18-22]. TLN-1 overexpression has been reported to enhance prostate cancer cell adhesion, migration, and invasion by activating survival signals and conferring resistance to anoikis [19]. TLN-1 overexpression could serve as a diagnostic marker for aggressive phenotypes and a potential target for treating oral squamous cell carcinoma (OSCC) [23]. In addition, kinesin family member 14 (KIF14) and TLN-1 expression levels predict a better outcome after cytotoxic chemotherapy, and inhibition of these genes sensitizes triple-negative breast cancer (TNBC) cells to therapeutic intervention [24]. In a retrospective study of banked tissue samples, alpha-actinin and TLN were found to be completely absent in both endometriosis and endometrioid carcinomas [12, 25]. In HCC research, Chinese investigators have observed that TLN-1 protein and mRNA levels in HCC tissues are significantly lower than those in the adjacent non-cancerous tissues [12]. However, Japanese investigators have reported that TLN-1 is upregulated in HCC [17], and Egyptian studies showed that TLN-1 serum levels in HCC patients are significantly higher [26].

To date, the role and function of TLN-2, as a homologous gene of TLN-1, in tumors remains unclear. Studies have demonstrated that the N-terminal TLN-2 FERM domain binds to $\beta 1 D$-integrin with a higher affinity than that of TLN-1 [27, 28]. Studies using cultured cells have clearly established that TLN-2 can compensate for the loss of TLN-1, supporting cell spreading and focal adhesion (FA) assembly in TLN-1 knockout or knockdown cells $[27,29,30]$. TLN-1 knockout is embryonic lethal at gastrulation in mice, whereas TLN-2 knockout mice are viable and fertile $[6,7,15]$.

Previously, we showed that TLN-1 and TLN-2 mRNA and protein expressions differ significantly among five human HCC cell lines and the human normal liver $\mathrm{LO}_{2}$ cell line [8]; indeed, TLN-1 and TLN-2 expression levels might be related to invasion and migration in human hepatocellular carcinoma (HCC). To further assess the role of TLN-1 and TLN-2 in HCC, MHCC-97 L cells, which highly express TLN-1, were selected for gene knockdown using RNA interference. The effects of TLN-1/2 silencing on HCC malignancy potential in vivo were also evaluated.

\section{Methods}

The protocols in this study were approved by the Ethics Committee of Anhui Medical University. Animal testing was performed in accordance with the international guiding principles for biomedical research.

\section{Cell culture}

Human hepatocellular carcinoma MHCC-97 L cells were provided by the GanDanYi Experiment Center of Huashan Hospital affiliated to Fudan University, Shanghai (China), and cultured in Dulbecco's modified Eagle's medium (DMEM) (Invitrogen, Carlsbad, CA, USA) containing $10 \%$ fetal bovine serum (FBS) (Invitrogen, Carlsbad, CA, USA) and antibiotics (penicillin G/streptomycin, $50 \mu \mathrm{g} / \mathrm{ml}$ ) (Sangon Biotech Co., Ltd., Shanghai, China), in a humid environment at $37{ }^{\circ} \mathrm{C}$ with $95 \%$ normal air and $5 \% \mathrm{CO}_{2}$.

\section{Lentivirus-mediated stableTLN-1 knockdown in the MHCC-97 L cells}

A shRNA sequence targeting the TLN-1 gene (GenBank. No. NM_006289.3) (5'-GCTCGAGATGGCAAGCTTA AA-3') and one nonspecific sequence 5'-TTCTCCGAA CGTGTCACGTTTC-3' (scramble shRNA) used as the negative control which did not have any homology with the target gene were designed and packaged into Lentivirus and transduced into $293 \mathrm{~T}$ cells by Shanghai GenePharma Co., Ltd (China).

For TLN-1 silencing, $0.5 \times 10^{5}$ MHCC-97 L cells were plated in 24-well plates in complete culture medium for $24 \mathrm{~h}$. Then, cells were transduced for $72 \mathrm{~h}$ with lentivirusmediated TLN-1-shRNA and scramble shRNA, respectively (Shanghai GenePharma Co., Ltd, China), under puromycin selection. Afterwards, the transduced cells were cultured in DMEM containing $10 \%$ FBS and $3 \mu \mathrm{g} / \mathrm{ml}$ of puromycin for 12 days (changing the medium every 3 days), and stably transduced cells were obtained. TLN-1 mRNA and protein levels were assessed by real-time RT-PCR and western blot.

\section{Real-time RT-PCR}

Total RNA was extracted using RNeasy Miniprep Kit (Sangon Biotech Co., Ltd., Shanghai, China) according to the manufacturer's instructions, and treated with Turbo DNase (Ambion, Austin, TX, USA). RNA purity was determined by measuring absorbance at 260 and $280 \mathrm{~nm}(\mathrm{~A} 260 / 280)$. DNase-treated total RNA $(1 \mu \mathrm{g})$ was reverse-transcribed using Superscript III reverse 
transcriptase (Invitrogen, Carlsbad, CA, USA) and $500 \mathrm{ng}$ of random primers (Promega, Madison, WI, USA). Glyceraldehyde 3-phosphate dehydrogenase (GAPDH) was used as an internal control. The following primer pairs were used for TLN-1, TLN-2 and GAPDH (http://www.rtprimerdb.org/): TLN-1: sense, 5'- TGTAGAGGAGCACGAGA CGC -3' and anti-sense, 5'- AAGGAGACAGGGTGG GAGC -3'; TLN-2: sense, 5'-CTGAGGCTCTTTTCA CAGCA-3' and anti-sense, 5'-CTCATCTCATCTGCC AAGCA-3'; GAPDH: sense: 5'-CATGAGAAGTATGA CAACAGCCT-3' and anti-sense, 5'- AGTCCTTCC ACGATACCAAAGT-3'. Relative gene expression was quantified by real-time PCR using SYBR Premix Ex Taq ${ }^{\text {Tn }}$ II (TaKaRa Bio, Dalian, China) on a Lightcycler 480 RealTime PCR System (Roche Diagnostics, Meylan, France). Reactions were carried out with initial denaturation $\left(95^{\circ} \mathrm{C}\right.$ for $3 \mathrm{~min}$ ) followed by 40 cycles of $95{ }^{\circ} \mathrm{C}$ for $12 \mathrm{~s}, 62{ }^{\circ} \mathrm{C}$ for $30 \mathrm{~s}$, and $72{ }^{\circ} \mathrm{C}$ for $30 \mathrm{~s}$. The cycle threshold $(\mathrm{Ct})$ was defined as the number of cycles required for the fluorescent signal to cross the threshold. First, $\Delta \mathrm{Ct}=\mathrm{Ct}_{\mathrm{Gene}}-\mathrm{Ct}_{\mathrm{GAPDH}}$. Then, $\Delta \Delta \mathrm{Ct}=\Delta \mathrm{Ct}$ treated $-\Delta \mathrm{Ct}$ control. Ratios were derived as proposed elsewhere [31].

\section{Western blotting}

Cells were lysed in M-PER Mammalian Protein Extraction Reagent (Thermo, USA), and equal amounts of protein were resolved by $6 \%$ sodium dodecyl sulfatepolyacrylamide gel electrophoresis (SDS-PAGE) and blotted onto polyvinylidene difluoride (PVDF) membranes (Millipore). The following specific primary antibodies were used: anti-TLN-1(ab78291, Abcam, Cambridge, MA, USA), anti-TLN-2 (ab105458, Abcam, Cambridge, MA, USA) and anti- $\beta$-actin (A5441, SIGMA). Proteins were detected using Pierce ECL Western Blotting Substrate (Thermo). Band intensities were compared using the Gel-Pro analyzer software.

\section{Cell cycle evaluation}

Cells were fixed in $70 \%$ ethanol overnight at $4{ }^{\circ} \mathrm{C}$. After PBS washes and incubation in PBS containing $50 \mu \mathrm{g} / \mathrm{mL}$ propidium iodide (PI) and $200 \mathrm{mg} / \mathrm{mL}$ RNase A for $30 \mathrm{~min}$ in the dark at room temperature, cells were subsequently subjected to flow cytometry analysis. Cell cycle progression was analyzed via fluorescence-activated cell sorting (FACS) on a Partec Flow Max flow cytometer (Partec, Münster, Germany).

\section{Anoikis evaluation}

MHCC-97 L and stably transduced cells were plated in poly-HEMA-coated 6-well plates. After 12, 48 and $72 \mathrm{~h}$ of culture, cells were harvested, rinsed with PBS, and apoptosis was evaluated using the Annexin V-PE/7-AAD apoptosis detection kit (KGA1017, KeyGen Biotech, Nanjing, China) on BD FACS Calibur flow cytometer.
The percentage of apoptotic cells was derived as the sum of cell fractions displaying early apoptosis (Annexin $\mathrm{V}$-positive) and late apoptosis (7-AAD-positive).

\section{Transwell migration and invasion assays}

A transwell chamber containing an $8-\mu \mathrm{m}$ pore polycarbonate membrane filter was coated either with (invasion) or without (migration) matrigel (BD, USA), and inserted in a 24-well culture plate. $10^{5}$ cells/well in $0.2 \mathrm{~mL}$ serum-free DMEM was added to the upper chambers of the plates, and DMEM containing $10 \%$ fetal bovine serum in the lower chambers. The plate was then incubated at $37{ }^{\circ} \mathrm{C}$ in presence of $5 \% \mathrm{CO}_{2}$ for $24 \mathrm{~h}$, and the filter removed. Cells in the upper chamber that did not migrate were scraped away with a cotton swap; trans-membrane cells were fixed in $4 \%$ paraformaldehyde for $30 \mathrm{~min}$ and dyed using crystal violet for $25 \mathrm{~min}$. Migrating or invading cells were photographed using an inverted optical microscope (Olympus, Tokyo, Japan). Quantification of migrating or invading cells was determined using the 3-(4,5-dimethylthiazol-2-yl)-2,5-diphenyltetrazolium bromide (MTT) method.

\section{Scratch test}

Cells were resuspended in complete medium, with density adjusted to $1 \times 10^{6}$ cells $/ \mathrm{ml}$. Then, $3 \mathrm{ml}$ of cell suspension was added to each well of a 6-well plate. At $80 \%$ confluence, the medium was removed, and a scratch with a standard $200 \mu$ pipette tip was made on the cell layer, equidistant from the dish edges. Wound healing was quantified using the Image $J$ software (National Institutes of Health, Bethesda, MD, USA) as the percentage of wound healing area $=[$ Cell-free area $(0 \mathrm{~h})$ - Cell-free area $(72 \mathrm{~h})] /$ Cell-free area $(0 \mathrm{~h})$.

\section{Xenograft nude mouse model}

Specific-pathogen-free (SPF)-grade adult nude mice (4-6 weeks of age) were housed with pathogen-free fodder, equipment, and environment. Then, $0.2-\mathrm{ml}$ aliquots of non-transduced, and TLN-1 shRNA and scramble shRNA transduced MHCC-97 L cells, respectively $\left(5 \times 10^{7}\right.$ cells/200 $\mu \mathrm{l}$ of PBS) were subcutaneously injected at the inguinal region of nude mice in a SPF-grade ultraclean work station. After 20 days, tumor diameters were measured every 3 days with Vernier calipers. Tumor volume (TV) was calculated according to the formula: TV $\left(\mathrm{mm}^{3}\right)=\mathrm{d}^{2} \times \mathrm{D} / 2$, where $\mathrm{d}$ and $\mathrm{D}$ represent the shortest and the longest diameters, respectively. The mice were sacrificed at 29 days after cell implantation, and the tumors were extracted.

\section{Statistical analysis}

Experimental data were analyzed using the Statistical Package for the Social Sciences (SPSS) 17.0 software (SPSS 
Inc., Chicago, IL, USA) and Microsoft Office Excel 2010 (Microsoft, Redmond, WA, USA). Data are mean \pm standard deviation (SD), and groups were compared using independent samples $t$ test and one-way analysis of variance (ANOVA). $P<0.05$ was considered statistically significant.

\section{Results}

\section{Establishment of a stable TLN-1 knockdown MHCC-97 L} cell line

As shown in Fig. 1, a stable TLN-1 knockdown MHCC$97 \mathrm{~L}$ cell line was successfully established. According to fluorescence microscopy, transduction efficiency in MHCC-97 L cells (the percentage of GFP-positive cells) was $>70 \%$ (Fig. 1a). Furthermore,TLN-1 mRNA and protein levels in the cells transduced with lentivirusmediated TLN-1-shRNA (experimental group) were markedly reduced compared with the non-transduced cells (blank controls) and cells transduced with lentivirus-mediated scramble-shRNA (negative controls) after $72 \mathrm{~h}$ (both $P<0.01$ ), as shown by real-time RTPCR (Fig. 1b) and Western blot (Fig. 1c).
Effects of TLN-1 knockdown on TLN-1 and TLN-2 mRNA and protein expressions in MHCC-97 $L$ cells

The transduced cells were assessed at different time points for their mRNA and protein expression levels. As shown in Fig. 2a, TLN-1 mRNA levels were starkly reduced after gene silencing compared with the blank and negative control groups, at 12,48 , and $72 \mathrm{~h}$ (all $P<0.01$ ). Although TLN-2 gene expression was less affected than that of TLN-1, significant differences were obtained at 48 and $72 \mathrm{~h}$ in the experimental group compared with the blank and negative control groups (both $P<0.01$, Fig. 2b). The same trend was observed for protein expression, and significantly decreased TLN-1 and TLN-2 were observed at all time points (all $P<0.01$, Fig 2 c and d).

\section{Effects of TLN-1/2 knockdown on cell cycle distribution and Anoikis in MHCC-97 L cells}

As shown in Fig. 3a, TLN-1/2 knockdown cells showed significantly more cells in the G0/G1 phase (79.24 \%) in comparison with both blank (65.36 \%) and negative

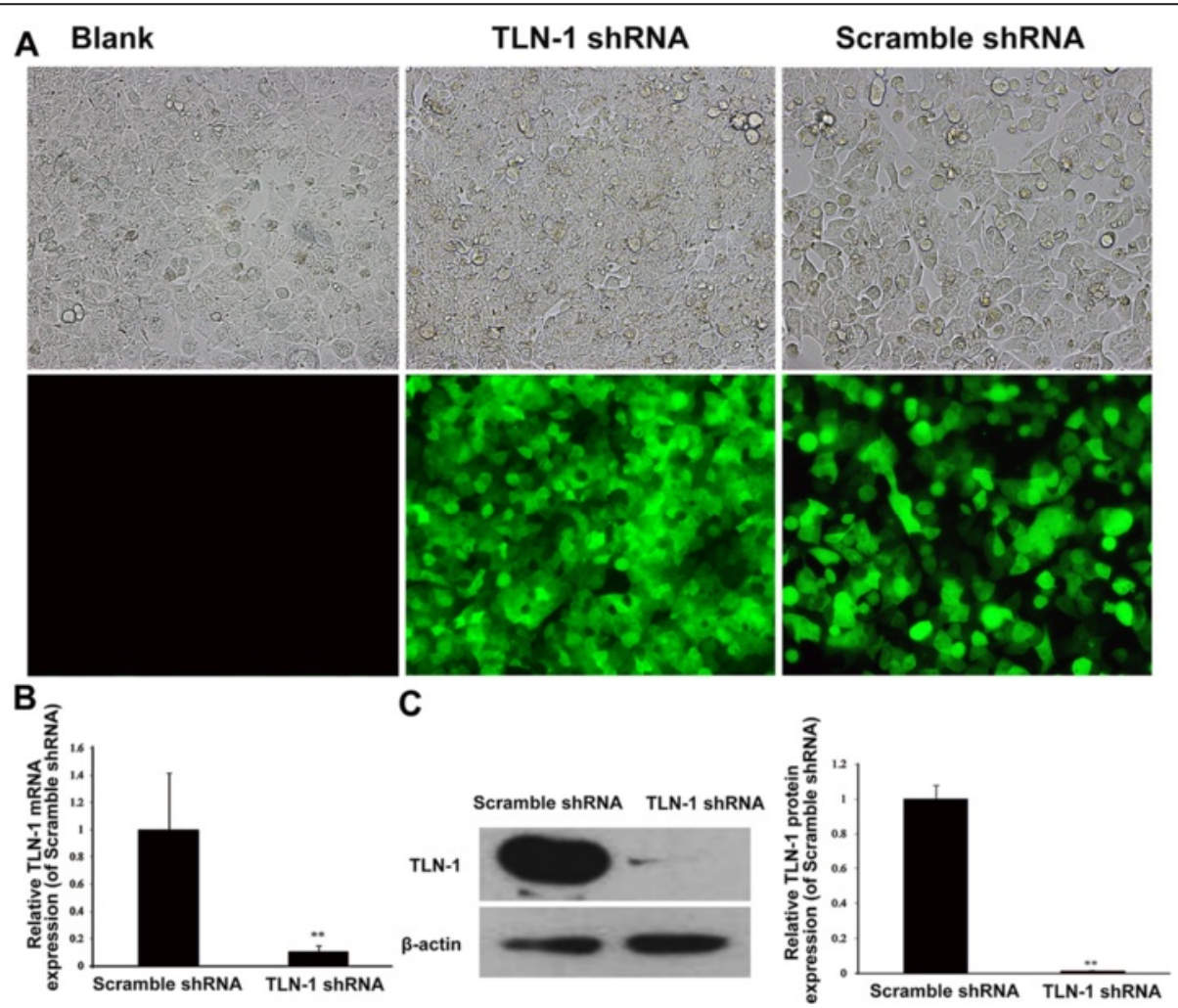

Fig. 1 Lentivirus-mediated stable Talin-1 (TLN-1) knockdown in the minimally metastatic HCC MHCC-97 L cells. Blank: non-transduced MHCC-97 L cells; TLN-1 shRNA: MHCC-97 L cells transduced with lentivirus-mediated TLN-1 shRNA; Scramble shRNA: MHCC-97 L cells transduced with lentivirusmediated scramble shRNA. a According to fluorescence microscopy, transduction efficiency in MHCC-97 L cells (the percentage of GFP-positive cells) was $>70 \%$ at $72 \mathrm{~h}$ (magnification: $\times 200$ ). $\mathbf{b}$ TLN-1 mRNA expression levels were determined by real-time RT-PCR at $72 \mathrm{~h}$ after transduction, with GAPDH used as an internal control. c TLN-1 protein expression levels were determined by Western blot at $72 \mathrm{~h}$ after transduction. $\beta$-actin was used as an internal control. Data are mean \pm Standard deviation (SD). ${ }^{*} P<0.01$ vs. scramble shRNA 


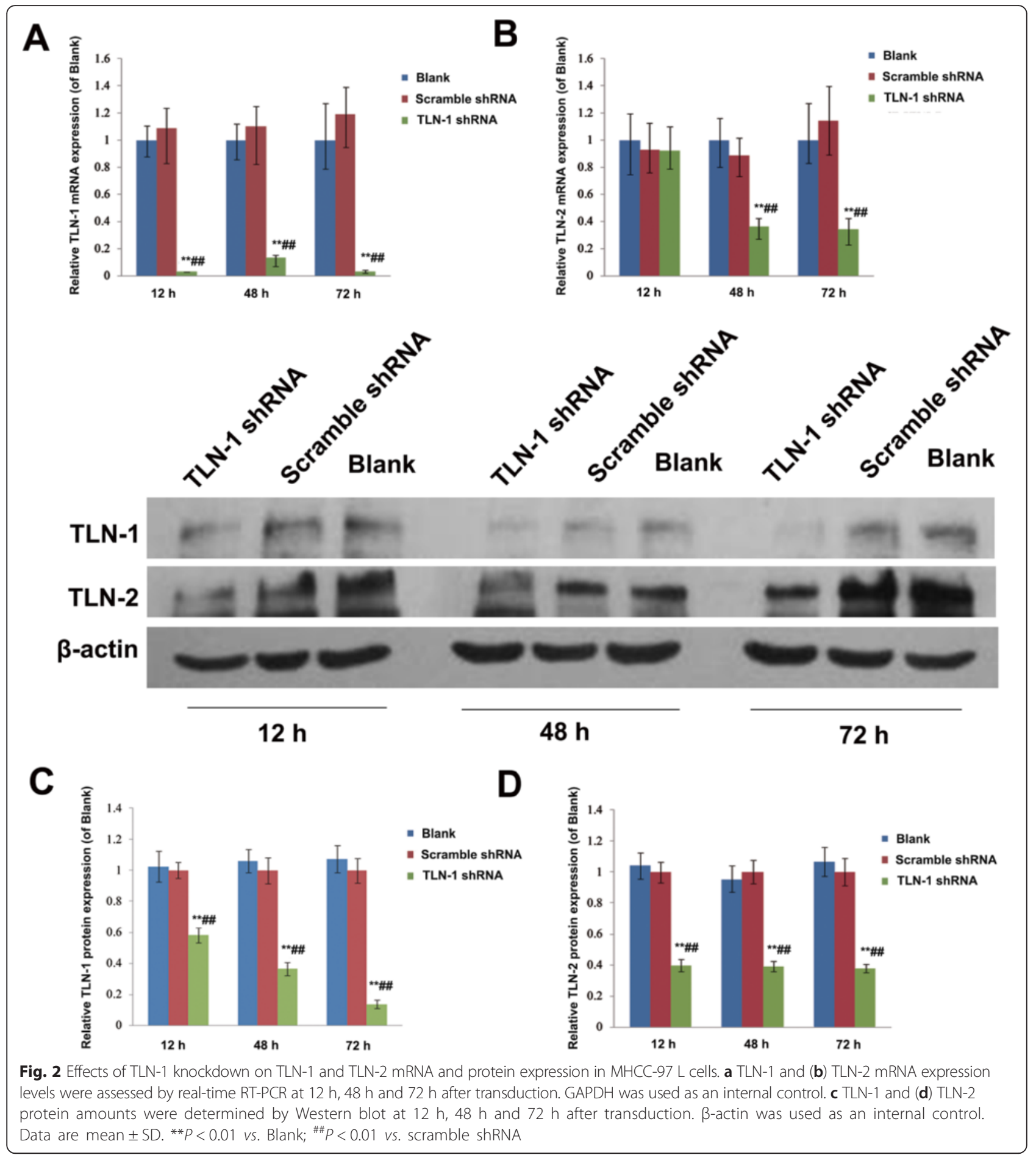

(62.69 \%) control groups; conversely, less cells were found in G2/M and S phases in the experimental group compared with controls. Interestingly, anoikis was enhanced in the experimental group in comparison with controls $(P<0.01)$ (Fig. 3b).
Effects of TLN-1/2 knockdown on migration and invasion in MHCC-97 L cells

As shown in Fig. 4a and b, respectively, migration and invasion abilities of MHCC-97 L cells were markedly reduced after TLN-1/2 knockdown (all $P<0.01$ ) compared 


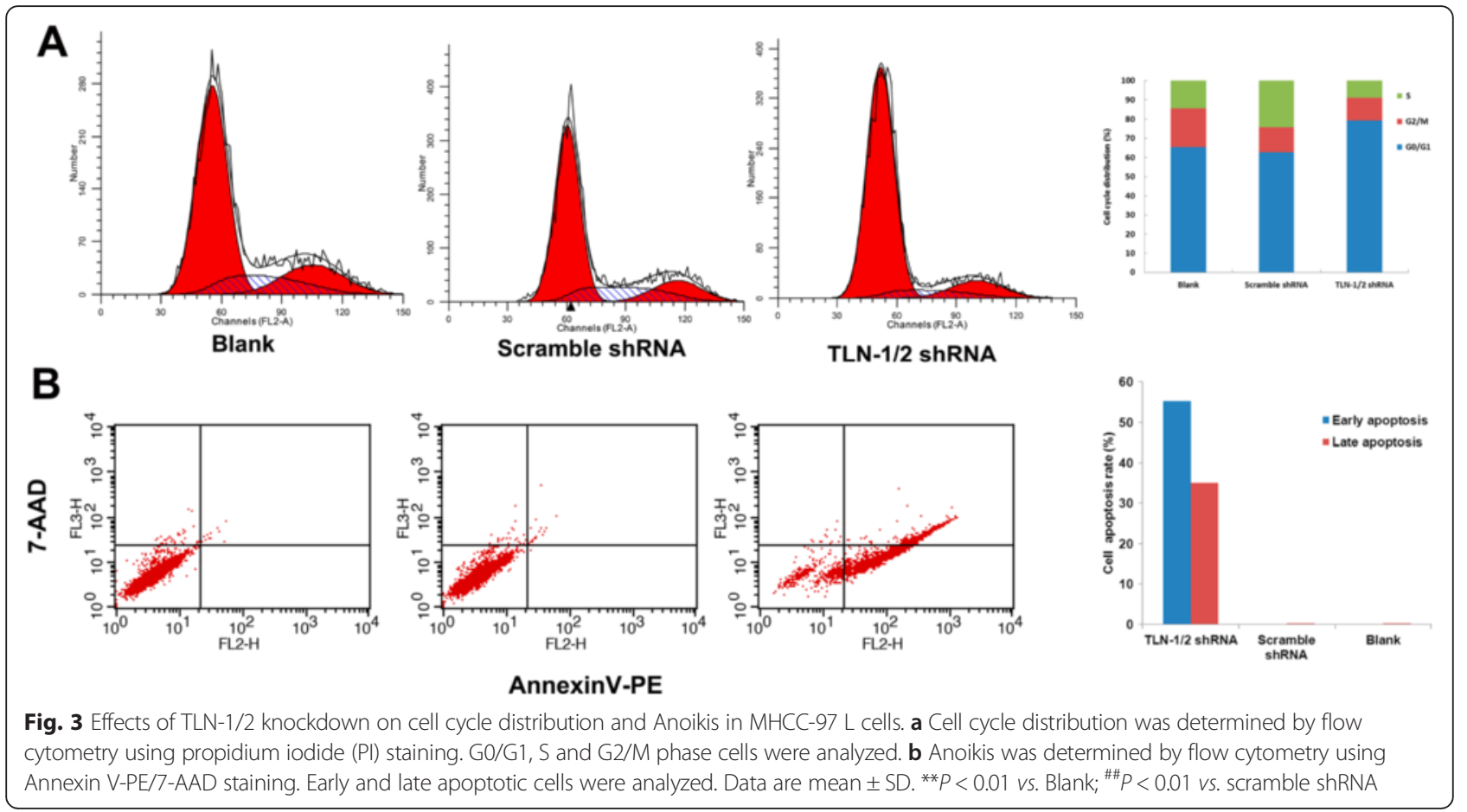

with controls. This was confirmed by the wound healing assay, in which TLN-1/2 knockdown cells showed decreased migration distance compared with both control groups (Percentage of wound healing area: experimental group: $32.6 \pm 0.7 \%$ vs. negative controls: $50.1 \pm 0.6 \%$ and blank controls: $53.6 \pm 0.6 \%$, both $P<0.01$ ) (Fig. 4c).

\section{TLN-1/2 knockdown inhibits tumor growth in vivo}

Compared with the blank and negative control groups, TLN-1 shRNA transduced MHCC-97 L cells yielded smaller tumor volume in nude mice after subcutaneous injection, showing weaker cell tumorigenicity. The differences were statistically significant at 29 days after cell inoculation $(P<0.05$, Fig. 5a). Representative tumors are shown in Fig. 5b.

\section{Discussion}

The roles of TLN-1 and TLN-2 in HCC are not completely understood. We previously assessed five human $\mathrm{HCC}$ cell lines and normal liver $\mathrm{LO}_{2}$ cells, and showed that TLN-1 protein expression levels in MHCC-97 L cells are highest [8]. In this study we used the lentiviral interference technology to knockdown TLN-1 expression in MHCC-97 L cells, generating a stable transduced cell line. As shown above, TLN-1 knockdown MHCC$97 \mathrm{~L}$ cells showed reduced TLN-1 mRNA and protein expressions, as well as arrested cell cycle in the G0/G1 phase, enhanced anoikis, decreased invasion and migration abilities, confirming the involvement of TLN-1 in HCC progression.
Recent studies have demonstrated the complexity of the mammalian TLN-2 gene which may have at least three different protein isoforms expressed in a tissuespecific manner. Additionally, alternatively spliced transcripts have been described for the vertebrate TLN-2 as well as the unique ancestral TLN gene, which is closely related to TLN-2 $[6,17]$. Furthermore, TLN-1 and TLN2 encode proteins with $74 \%$ sequence identity. Thus we further investigated the TLN-2 gene and protein expression by real-time RT-PCR and western blot, respectively, after TLN-1 knockdown. We unexpectedly discovered that TLN-2 expression levels were also decreased in stable TLN-1 knockdown cells. These results indicated that the selected shRNA sequence targeting the TLN-1 gene was directed towards the consensus sequence of TLN-2. Thus, the observed changes of cell cycle distribution, anoikis, migration and invasion, and tumor formation inhibition in vivo were likely associated with the down-regulation of TLN-1 and TLN-2, not just TLN-1.

In this study, TLN-1/2 knockdown resulted in decreased malignancy potential of MHCC-97 L cells in vitro as demonstrated with cell cycle arrest at the G0/G1 phase and enhanced anoikis, as well as decreased migration and invasion capabilities. These corroborate previous reports that TLN-1 is involved in integrin activation $[7,8]$, which leads to the regulation of adhesion, invasion, proliferation, anoikis, survival, tumor progression and metastasis [7-11,32]. Interestingly, our in vivo mouse xenograft model confirmed the in vitro findings as smaller tumors were obtained in animals inoculated with 

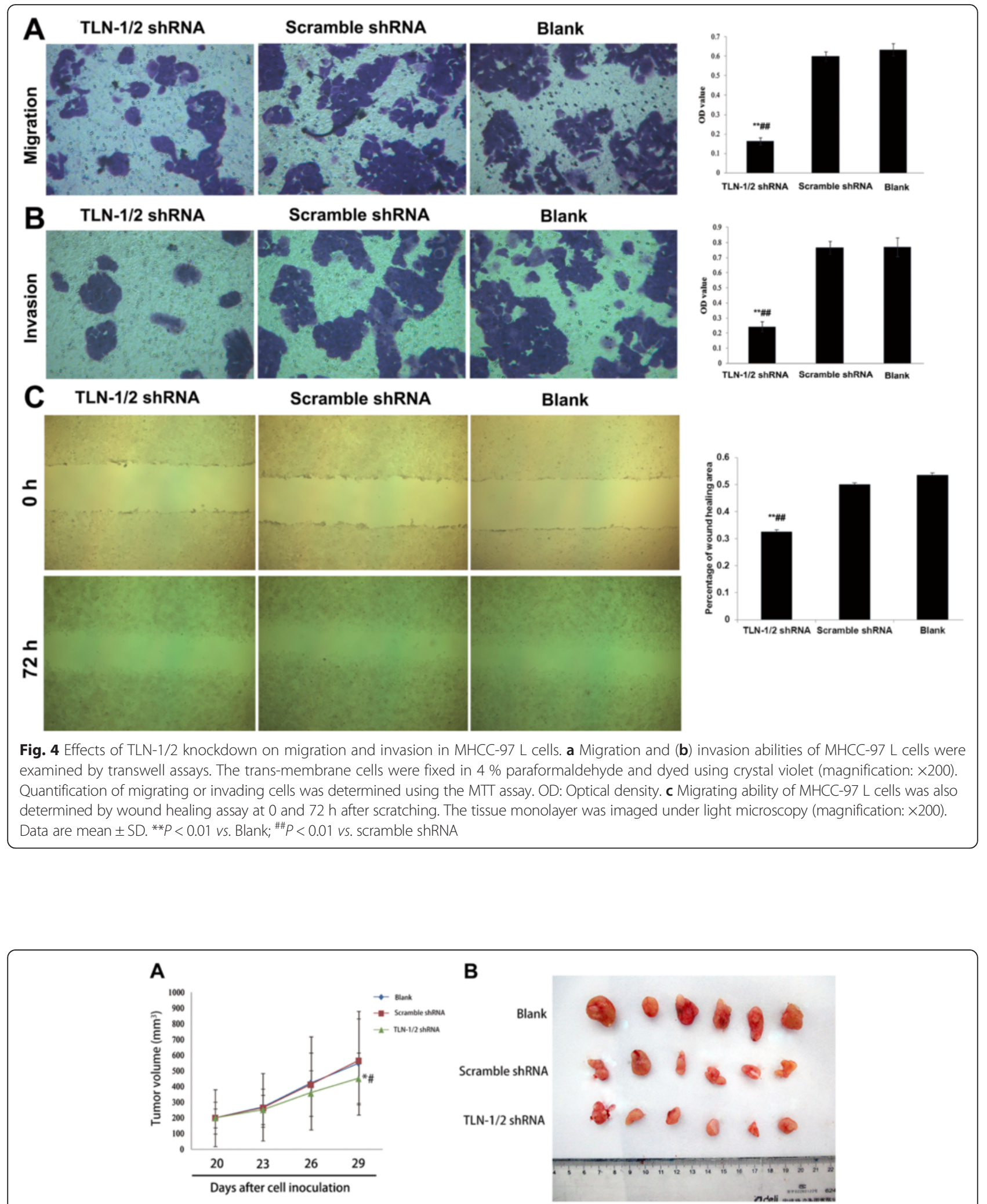

Fig. 5 TLN-1/2 knockdown inhibits tumor growth in vivo. MHCC-97 L cells (Blank), MHCC-97 $L$ cells transduced with lentivirus-mediated TLN-1/2 shRNA (TLN-1/2 shRNA) or lentivirus-mediated scramble shRNA (Scramble shRNA) $\left(5 \times 10^{7}\right.$ cells/200 $\mu$ l of PBS) were subcutaneously injected at the inguinal region of nude mice. a Tumor volume $\left(\mathrm{mm}^{3}\right)$ was assessed by calipers every 3 days 20 days after cell inoculation. $\mathbf{b}$ The mice were sacrificed at 29 days after cell inoculation, and the tumors were extracted. Data are mean \pm SD. ${ }^{*} P<0.05$ vs. Blank; ${ }^{P} P<0.05$ vs. scramble shRNA 
the TLN-1/2 knockdown MHCC-97 L cells in comparison with those of the control (blank and negative) groups. Interestingly, KIF14 and TLN-1 inhibition was found to sensitize triple-negative breast cancer (TNBC) cells to therapeutic intervention [19]. However, Talin 1 was recently proposed to be a novel player in the anti-metastatic signaling network of miR-124 [33]. Taken together, these findings suggest that Talin1/2 might regulate HCC invasion and migration through complex mechanisms that are not completely understood.

Although TLN-1 silencing resulted in reduced protein and mRNA expressions of both TLN-1 and 2, it is likely that specific targeting of TLN-2 would have different outcomes. Therefore, we plan in the near future to design specific shRNA aimed at both TLN-1 and TLN-2 to further assess the roles of these two proteins in $\mathrm{HCC}$ metastasis and invasion. Alternatively, commercially available TLN-1- and TLN-2-specific monoclonal antibodies will be used to elucidate individual and combined effects of TLN-1 and TLN-2 on primary HCC invasion and migration.

\section{Conclusion}

Our results showed that the levels of both TLN-1 and TLN-2 correlate with tumorigenicity in human HCC, indicating that these molecules constitute useful molecular targets in HCC diagnosis and/or treatment.

\begin{abstract}
Abbreviations
ANOVA: one-way analysis of variance; DMEM: Dulbecco's Modified Eagle's Medium; ECM: extracellular matrix; FA: Focal adhesion; FACS: fluorescenceactivated cell sorting; FAK: focal adhesion kinase; FBS: fetal bovine serum; GAPDH: glyceraldehyde 3-phosphate dehydrogenase; HCC: Hepatocellular carcinoma; KIF14: kinesin family member 14; mRNA: messenger ribonucleic acid; PBS: Phosphate Buffer Saline; PVDF: polyvinylidene difluoride; RT-PCR: real time reverse transcriptase-PCR; SD: standard deviation; SDS-PAGE: sodium dodecyl sulfate-polyacrylamide gel electrophoresis; SPF: specific-pathogen-free; SPSS: Statistical Package for the Social Sciences; TNBC: triple-negative breast cancer; TV: tumor volume.
\end{abstract}

\section{Competing interests}

The authors declare that they have no competing interests.

\section{Author's contributions}

$\mathrm{K}-\mathrm{pF}$ and $\mathrm{Y}-\mathrm{BQ}$ contributed equally to this work; $\mathrm{Y}-\mathrm{BQ}$ and $\mathrm{K}-\mathrm{pF}$ designed the research; $\mathrm{K}-\mathrm{pF}$ performed the research; $\mathrm{K}-\mathrm{pF}$ provided the analytic tools; $\mathrm{Y}-\mathrm{BQ}, \mathrm{K}-\mathrm{pF}$ analyzed the data; Y-BQ, K-pF wrote the paper; and Y-CX, Y-HR, WD and S-mZ participated in manuscript writing. All authors read and approved the final manuscript.

\section{Acknowledgements}

This research was supported by the Natural Science Foundation of Anhui Province (No. 1208085MH137) and the Natural Science Foundation of Anhui Province (No. 12070403065). We thank Professor Wang Ming-li, the Director of the Department of Microorganisms, and Professor Shen Ji-jia, the Director of the Department of Parasitology at the Basic Medical College of Anhui Medical University. We also wish to thank all of the teachers at the Department of General Surgery in Ward Three at The First Affiliated Hospital of Anhui Medical University.
Received: 24 March 2015 Accepted: 19 January 2016

Published online: 28 January 2016

\section{References}

1. Rapti I, Hadziyannis S. Risk for hepatocellular carcinoma in the course of chronic hepatitis $B$ virus infection and the protective effect of therapy with nucleos(t)ide analogues. World J Hepatol. 2015;7(8):1064-73. doi:10.4254/wjh.v7.i8.1064.

2. Torrecilla S, Llovet JM. New molecular therapies for hepatocellular carcinoma. Clin Res Hepatol Gastroenterol. 2015;39 Suppl 1:S80-5. doi:10.1016/j.clinre.2015.06.016.

3. Schlachterman A, Craft Jr WW, Hilgenfeldt E, Mitra A, Cabrera R. Current and future treatments for hepatocellular carcinoma. World J Gastroenterol. 2015;21(28):8478-91. doi:10.3748/wjg.v21.i28.8478.

4. Praekelt U, Kopp PM, Rehm K, Linder S, Bate N, Patel B, et al. New isoform-specific monoclonal antibodies reveal different sub-cellular localisations for talin1 and talin2. Eur J Cell Biol. 2012;91(3):180-91. doi:10.1016/j.ejcb.2011.12.003.

5. Debrand E, El Jai Y, Spence L, Bate N, Praekelt U, Pritchard CA, et al. Talin 2 is a large and complex gene encoding multiple transcripts and protein isoforms. Febs j. 2009;276(6):1610-28. doi:10.1111/j.1742-4658.2009.06893.x.

6. Monkley SJ, Kostourou V, Spence L, Petrich B, Coleman S, Ginsberg MH, et al. Endothelial cell talin1 is essential for embryonic angiogenesis. Dev Biol. 2011;349(2):494-502. doi:10.1016/j.ydbio.2010.11.010.

7. Monkley SJ, Pritchard CA, Critchley DR. Analysis of the mammalian talin2 gene TLN2. Biochem Biophys Res Commun. 2001;286(5):880-5. doi:10.1006/bbrc.2001.5497.

8. Fang KP, Zhang JL, Ren YH, Qian YB. Talin-1 correlates with reduced invasion and migration in human hepatocellular carcinoma cells. Asian Pac J Cancer Prev. 2014;15(6):2655-61.

9. Conti FJ, Monkley SJ, Wood MR, Critchley DR, Muller U. Talin 1 and 2 are required for myoblast fusion, sarcomere assembly and the maintenance of myotendinous junctions. Development. 2009;136(21):3597-606. doi:10.1242/dev.035857

10. Tsujioka M, Yoshida $K$, Inouye $K$. Talin B is required for force transmission in morphogenesis of Dictyostelium. Embo j. 2004;23(11):2216-25. doi:10.1038/sj.emboj.7600238.

11. Senetar MA, Moncman CL, McCann RO. Talin2 is induced during striated muscle differentiation and is targeted to stable adhesion complexes in mature muscle. Cell Motil Cytoskeleton. 2007;64(3):157-73. doi:10.1002/cm.20173

12. Zhang JL, Qian YB, Zhu LX, Xiong QR. Talin1, a valuable marker for diagnosis and prognostic assessment of human hepatocelluar carcinomas. Asian Pac J Cancer Prev. 2011;12(12):3265-9.

13. Senetar MA, McCann RO. Gene duplication and functional divergence during evolution of the cytoskeletal linker protein talin. Gene. 2005;362:141-52. doi:10.1016/j.gene.2005.08.012.

14. Wang Y, Litvinov Rl, Chen X, Bach TL, Lian L, Petrich BG, et al. Loss of PIP5Klgamma, unlike other PIP5KI isoforms, impairs the integrity of the membrane cytoskeleton in murine megakaryocytes. J Clin Invest. 2008;118(2):812-9. doi:10.1172/jci34239.

15. Chen NT, Lo SH. The N-terminal half of talin2 is sufficient for mouse development and survival. Biochem Biophys Res Commun. 2005;337(2):670-6. doi:10.1016/j.bbrc.2005.09.100.

16. Critchley DR. Cytoskeletal proteins talin and vinculin in integrin-mediated adhesion. Biochem Soc Trans. 2004;32(Pt 5):831-6. doi:10.1042/bst0320831.

17. Kanamori H, Kawakami T, Effendi K, Yamazaki K, Mori T, Ebinuma H, et al. Identification by differential tissue proteome analysis of talin-1 as a novel molecular marker of progression of hepatocellular carcinoma. Oncology. 2011;80(5-6):406-15. doi:10.1159/000330734

18. Giancotti FG, Ruoslahti E. Integrin signaling. Science. 1999;285(5430):1028-32.

19. Sakamoto S, McCann RO, Dhir R, Kyprianou N. Talin1 promotes tumor invasion and metastasis via focal adhesion signaling and anoikis resistance. Cancer Res. 2010;70(5):1885-95. doi:10.1158/0008-5472.can-09-2833.

20. Fornaro M, Manes T, Languino LR. Integrins and prostate cancer metastases. Cancer Metastasis Rev. 2001;20(3-4):321-31.

21. Calderwood DA. Integrin activation. J Cell Sci. 2004;117(Pt 5):657-66. doi:10.1242/jcs.01014.

22. Alam N, Goel HL, Zarif MJ, Butterfield JE, Perkins HM, Sansoucy BG, et al. The integrin-growth factor receptor duet. J Cell Physiol. 2007;213(3):649-53. doi:10.1002/jcp.21278. 
23. Lai MT, Hua CH, Tsai MH, Wan L, Lin YJ, Chen CM, et al. Talin-1 overexpression defines high risk for aggressive oral squamous cell carcinoma and promotes cancer metastasis. J Pathol. 2011;224(3):367-76. doi:10.1002/path.2867.

24. Singel SM, Cornelius C, Batten K, Fasciani G, Wright WE, Lum L, et al. A targeted RNAi screen of the breast cancer genome identifies KIF14 and TLN1 as genes that modulate docetaxel chemosensitivity in triple-negative breast cancer. Clin Cancer Res. 2013;19(8):2061-70. doi:10.1158/1078-0432.ccr-13-0082.

25. Slater M, Cooper M, Murphy CR. The cytoskeletal proteins alpha-actinin, Ezrin, and talin are De-expressed in endometriosis and endometrioid carcinoma compared with normal uterine epithelium. Appl Immunohistochem Mol Morphol. 2007:15(2):170-4. doi:10.1097/01.pai.0000194762.78889.26.

26. Youns MM, Abdel Wahab AH, Hassan ZA, Attia MS. Serum talin-1 is a potential novel biomarker for diagnosis of hepatocellular carcinoma in Egyptian patients. Asian Pac J Cancer Prev. 2013;14(6):3819-23.

27. Debrand E, Conti FJ, Bate N, Spence L, Mazzeo D, Pritchard CA, et al. Mice carrying a complete deletion of the talin2 coding sequence are viable and fertile. Biochem Biophys Res Commun. 2012;426(2):190-5. doi:10.1016/j.bbrc.2012.08.061.

28. Anthis NJ, Wegener KL, Critchley DR, Campbell ID. Structural diversity in integrin/talin interactions. Structure. 2010;18(12):1654-66. doi:10.1016/j.str.2010.09.018.

29. Zhang X, Jiang G, Cai Y, Monkley SJ, Critchley DR, Sheetz MP. Talin depletion reveals independence of initial cell spreading from integrin activation and traction. Nat Cell Biol. 2008:10(9):1062-8. doi:10.1038/ncb1765.

30. Kopp PM, Bate N, Hansen TM, Brindle NP, Praekelt U, Debrand E, et al. Studies on the morphology and spreading of human endothelial cells define key inter- and intramolecular interactions for talin1. Eur J Cell Biol. 2010;89(9):661-73. doi:10.1016/j.jck.2010.05.003.

31. Livak KJ, Schmittgen TD. Analysis of relative gene expression data using real-time quantitative PCR and the 2(-Delta Delta C(T)) Method. Methods. 2001;25(4):402-8. doi:10.1006/meth.2001.1262.

32. Beaty BT, Wang Y, Bravo-Cordero JJ, Sharma VP, Miskolci V, Hodgson L, et al. Talin regulates moesin-NHE-1 recruitment to invadopodia and promotes mammary tumor metastasis. J Cell Biol. 2014;205(5):737-51. doi:10.1083/jcb.201312046.

33. Zhang W, Mao YQ, Wang H, Yin WJ, Zhu SX, Wang WC. MiR-124 suppresses cell motility and adhesion by targeting talin 1 in prostate cancer cells. Cancer Cell Int. 2015;15:49. doi:10.1186/s12935-015-0189-x.

\section{Submit your next manuscript to BioMed Central and we will help you at every step:}

- We accept pre-submission inquiries

- Our selector tool helps you to find the most relevant journal

- We provide round the clock customer support

- Convenient online submission

- Thorough peer review

- Inclusion in PubMed and all major indexing services

- Maximum visibility for your research

Submit your manuscript at www.biomedcentral.com/submit

) Biomed Central 